\title{
Association between transformational leadership and occupational burnout and the mediating effects of psychological empowerment in this relationship among CDC employees: a cross-sectional study
}

This article was published in the following Dove Press journal:

Psychology Research and Behavior Management

Chunli Liu'

Siqi Liu ${ }^{2}$

Shihan Yang ${ }^{2}$

Hui $W^{2}$

'College of Medical Information, China Medical University, Shenyang II0I22, People's Republic of China; ${ }^{2}$ Department of Social Medicine, School of Public Health, China Medical University, Shenyang II0122, People's Republic of China
Correspondence: Hui Wu

Department of Social Medicine, School of Public Health, China Medical University,

No. 77 Puhe Road, Shenyang North New Area, Shenyang II0122, People's Republic of China

Tel +86I 8900910568

Email hwu@cmu.edu.cn
Purpose: Centers for Disease Control and Prevention (CDC) is playing a vital role in protecting public health and safety. However, few studies have researched on the occupational burnout of CDC employees in the world. Previous studies have reported that transformational leadership could improve the level of psychological empowerment and ameliorate burnout of the employees. In this study, we aimed to analyze the association between transformational leadership and burnout and to test the mediating role of psychological empowerment in this relationship among CDC employees in China.

Methods: Maslach Burnout Inventory-Human Service Survey, Transformational Leadership Questionnaire, and Psychological Empowerment Scale were used to measure burnout, transformational leadership, and psychological empowerment. A total of 385 CDC employees (effective response rate: 96.25\%) were included in the study. We analyzed the association between transformational leadership and three subscales of burnout with hierarchical linear regression analyses. The mediating role of psychological empowerment was finally examined by asymptotic and resampling strategies.

Results: Transformational leadership was negatively associated with emotional exhaustion, depersonalization, and reduced personal accomplishment after controlling sociodemographic and working context characteristics. Transformational leadership and psychological empowerment, respectively, accounted for $9.3 \%$ and $12.3 \%$ of the variance in emotional exhaustion; $8.5 \%$ and $16.7 \%$ of the variance in depersonalization; and $6.7 \%$ and $10.0 \%$ of the variance in reduced personal accomplishment. We found that psychological empowerment played a partially mediating role on the relationship between transformational leadership and burnout. The proportion of psychological empowerment's mediating effect was $41.56 \%$ for emotional exhaustion, $50.62 \%$ for depersonalization, and $44.32 \%$ for reduced personal accomplishment.

Conclusions: It was suggested that transformational leadership could decrease the risk of burnout by the pathway of promoting the employee's psychological empowerment. Interventions focusing on transformational leadership and psychological empowerment should be of significance to cut burnout.

Keywords: burnout, transformational leadership, psychological empowerment, CDC

\section{Introduction}

Occupational burnout has been a hot topic in the field of occupational health management for many years. Researchers have found occupational burnout could cause a lot of harm not only to the employees and employers but also to the people 
receiving services. For instance, occupational burnout negatively affects the physical and mental health of employees, reduces the productivity of employees, and obstructs staff's social interaction in the work environment. ${ }^{1-3} \mathrm{~A}$ meta-analysis indicated that physician burnout involving emotional exhaustion, depersonalization, and reduced personal accomplishment reached epidemic levels, with about $50 \%$ prevalence. ${ }^{4}$ Physician burnout can result in negative effects on patient care, professionalism, physicians' physical health, mental health, and the health care system. It is necessary to explore how to reduce job burnout from the perspective of organizational behavior. Linzer et al have found workflow intervention and targeted quality improvement could significantly improve burnout. ${ }^{5}$ Are there other significant work environment variables associated with burnout? Does the factor have the potential to be an intervention target?

Leadership is important for the health and well-being of employees. Based on the occupational health theory and leadership theory, leadership is associated with potential occupational health risks or benefits. ${ }^{6,7}$ Leadership is an important determinant of employees' work-related health outcomes involving work well-being, work performance, and occupational satisfaction. ${ }^{8-10}$ Most of the studies are primarily on the positive work-related health states. However, little research has been done on the impact of leadership style on mental health, especially the negative health states, for instance, depression, anxiety, and burnout. Transformational leadership has attracted more empirical attention than other kinds of leadership in recent years. Transformational leadership mutually stimulates and engages relationship between leader and followers. Transformational leadership is positively associated with leadership effectiveness, for instance, job satisfaction, motivation, and performance of followers. ${ }^{11-13}$ A few studies suggested that managers could mitigate employee's job stress and burnout by transformational leadership. ${ }^{14,15}$ Some scholars have found that transformational leadership was associated with only emotional exhaustion, emotional exhaustion and depersonalization or all the job burnout' dimensions negatively. ${ }^{16-20}$ Gill has indicated that transformational leadership could mitigate job burnout among the hospitality industry employees. ${ }^{39}$

A few studies have found some evidence supporting the notion that transformational leadership has negative effects on employee stress, strain, and burnout. ${ }^{14,16}$ Holstad et al, for instance, demonstrated that the indirect negative relationship between transformational leadership and emotional strain via social support. ${ }^{21}$ Kenneth $\mathrm{L}$ et al have confirmed that transformational leadership ameliorated burnout indirectly. ${ }^{15}$ The organizational support and personal factors might mediate the relationship between transformational leadership and burnout. Some studies have suggested that transformational leadership is associated with psychological empowerment. ${ }^{22-25}$ Psychological empowerment can encourage employees to improve the ability to do tasks by adopting appropriating ways and have some influence on the working environment. ${ }^{26}$ Some studies have indicated that psychological empowerment was negatively correlated with occupational burnout significantly among the nurses and nurse educators. ${ }^{27-29}$ The higher the level of the empowerment of the respondents becomes, the lower the level of the burnout the respondents receives. Furthermore, some researchers pointed out that psychological empowerment had a role in reducing burnout among Canadian health care workers. ${ }^{30}$ Allameh et al have found a significant relationship between transformational leadership and psychological empowerment. ${ }^{31}$

Evidence suggests that health care workers are vulnerable to burnout. Nurses and residents are at a higher level of occupational burnout. ${ }^{32,33}$ The Centers for Disease Control and Prevention (CDC) is the public health institute which is managed by the government. The main goal of CDC is to protect public health and safety by means of controlling and preventing disease, injury, and disability. ${ }^{22}$ Employees working in CDC maybe also at a high level of burnout. First, CDC pays more attention to the infectious disease, environmental and occupational health, food safety, and injury prevention. When emergencies occur, CDC employees were at the forefront of efforts to rescue the wounded and control the outbreak. However, they are often ignored or confused as ordinary doctors and nurses for the low social awareness and influence of the CDC. Second, most of the CDC employees mentioned low salary, unfair promotion system, poor interpersonal relationship, and feelings of effort-reward imbalance. Third, rigid leadership style of employers, poor self-esteem, and career expectations of employees were also summarized as factors associated with intention to leave by CDC employees. Therefore, their work environment is more likely to induce burnout. CDC personnel are a group worthy of special attention from public health. However, few scholars have focused on the mental health of CDC employees.

Based on the analysis of the above conceptual framework and literature, we hypothesize that: 
Hypothesis 1: Transformational leadership is associated with three elements of burnout among CDC employees.

Hypothesis 2: The association between transformational leadership and three elements of employees' burnout was mediated by psychological empowerment.

\section{Methods}

\section{Participants}

The study has been approved by the Ethics Committee of China Medical University. Before the survey, we obtained the written informed consent signed by the respondents. Our scope of investigation is all the CDC employees in a city in the northeastern Chinese province. The CDC employees were investigated by layer cluster sampling, stratified by city direct unit, districts units, prefecturelevel cities units, and counties units. The questionnaires were sent to $\mathrm{CDC}$ employees of one city direct unit, three districts units, two prefecture-level cities units, and three counties units. Self-reported questionnaires were distributed to $400 \mathrm{CDC}$ employees in 2017, and 385 questionnaires were returned. All the 385 questionnaires are valid (the effective response rate: $96.25 \%$ ).

\section{Sociodemographic and working text characteristics}

We collected five demographic characteristics from each respondent including gender, age, educational level, employment status, and working overtime. Age was classified into three groups: $\leq 30,31-40$, and $\geq 41$ years. The educational level classification was based on the CDC employees' final educational experiences before attending the study. We divided the educational level into three categories: secondary school, junior college, and bachelor or above. We divided the employment status into two categories: permanent and contract. And we also required them to answer whether they work overtime recently (Yes or No).

\section{Instruments}

\section{Occupational burnout}

The Maslach Burnout Inventory screens for MBI scale were the most widely used and tested after its launch. It has been proved to have good internal consistency and reliability. ${ }^{34-37}$ We chose Maslach Burnout Inventory-Human Service Survey (MBI-HSS) to evaluate the occupational burnout of CDC employees in China. This is a 22-item questionnaire including 3 dimensions: Emotional exhaustion consists of 9 items; Depersonalization consists of 5 items; Reduced personal accomplishment consists of 8 items. ${ }^{35}$ All items are rated on a 7 -point Likert scale $(0=$ never; $1=\mathrm{a}$ few times a year; $2=$ once a month; $3=$ several times a month; $4=$ once a week; $5=$ several times a week; $6=$ everyday). For emotional exhaustion, depersonalization, and reduced personal accomplishment, the higher the score is, the higher the burnout of respondents are. Each scale measures its own unique dimension of burnout. The scores of the three subscales are independent and cannot be added. The Chinese version of the MBI-HSS has good reliability in Chinese populations. ${ }^{38,39}$ Moreover, in this study, the Cronbach alpha coefficients for emotional exhaustion, depersonalization, and reduced personal accomplishment are $0.729,0.752$, and 0.936 , respectively. In the present study, we chose the three dimensions of job burnout are dependent variables.

\section{Transformational leadership}

In 1985, Bass extended transformational leadership as leadership and performance beyond expectations. ${ }^{40}$ Based on Bass's multifactor leadership questionnaire, transformational Leadership Questionnaire (TLQ) was modified and translated in Chinese by Li CP with a good content reliability. ${ }^{41,42}$ TLQ scale includes 26 items and 4 dimensions: virtue, leadership, vision, and personal care. Virtue was measured by 8 items; Leadership was measured by 6 items; Vision was measured by 6 items; Personal care was measured by 6 items. Each item was answered by using a 5-point Likert scale ( $1=$ strongly disagree; $5=$ strongly agree). Total score ranges from 0 to 130 . A higher score of TLQ indicates a higher level of transformational leadership that the respondents perceived from their leaders are. In this study, Cronbach's alpha coefficient for the total scale is 0.933 .

\section{Psychological empowerment}

We selected Psychological Empowerment Scale (PES) which was developed by Spreitzer to assess the psychological empowerment. The Chinese version of the scale was widely used in Chinese populations for its good reliability. ${ }^{43}$ The total scale includes 12 items and 4 dimensions: meaningfulness, autonomy, competence, and impact. Each dimension has 3 items. Each item is scored on a 5-point Likert scale (1=strongly disagree; $5=$ strongly agree). Total score ranges from 0 to 60 . A higher score of PES represents a higher level of psychological empowerment that the respondents perceived are. In this study, Cronbach's alpha coefficient for the total scale is 0.975 . 


\section{Data analysis}

In this study, we used a cross-sectional design. We analyzed the data by SPSS 17.0. We compared the MBI scores of $\mathrm{CDC}$ employees according to their gender, age groups, educational level, employment status, and working overtime using independent-sample $t$-test and one-way ANOVA analyses. We used Spearman's correlation coefficients to test the correlation among variables. And we tested the mediating effect of psychological empowerment by using hierarchical linear regression method. In the first step of hierarchical linear regression, the control variables such as age, gender, and employment status were added. We selected the control variables based on the results of the $t$-test and the one-way ANOVA. We included significant variables as control variables in the regression. In the second step, transformational leadership was added. In the third step, psychological empowerment was added. All statistical tests were twosided $(\alpha=0.05)$.

In addition, we performed asymptotically and resampling strategies to examine whether the potential mediating effect of psychological empowerment was significant. ${ }^{44} \mathrm{We}$ modeled transformational leadership as independent variables, with Maslach Burnout subscales as the outcomes. Psychological empowerment was modeled as a mediator (as shown in Figure 1), and age, gender, and employment status as covariates. The aim of the first step is to identify the association between transformational leadership and burnout subscales (the c path). And the purpose of the second step is to test the mediating role of psychological empowerment $(a \times b$ path). If the c' path coefficient decreased than the c path coefficient or the c' path coefficient became insignificant, then the mediating role was examined. We acquired accelerated 95\% confidence intervals (B Ca 95\% CI) by bias-corrected bootstrapping $(5,000$ replications). And a $\mathrm{B} \mathrm{Ca} 95 \% \mathrm{CI}$ excluding 0 indicated that the mediating role is significant.

Figure 1 shows a mediation model. Step 1 represents the total effect of transformational leadership on burnout subscales (path c). Step 2 represents the direct effect (path c': transformational leadership on burnout subscales) and the indirect effects ( $\mathrm{a} \times \mathrm{b}$ path: transformational leadership on burnout subscales via mediator psychological empowerment).

\section{Results}

\section{Descriptive results}

Means, standard deviations of variables, and the results of Spearman's correlation have been shown in Table 1, the inter-correlations between transformational leadership, empowerment, and burnout facets were in the expected direction. Table 1 also showed the sociodemographic and working characteristics of participants and the distributions of burnout subscales.

\section{The mediation of psychological empowerment on the association between transformational leadership and burnout subscales}

Table 2 has shown the results of hierarchical regression analysis of emotional exhaustion after controlling demographic variables. Transformational leadership was negatively associated with emotional exhaustion. Transformational leadership explained $9.3 \%$ of the variance in emotional exhaustion among CDC employees. In addition, psychological
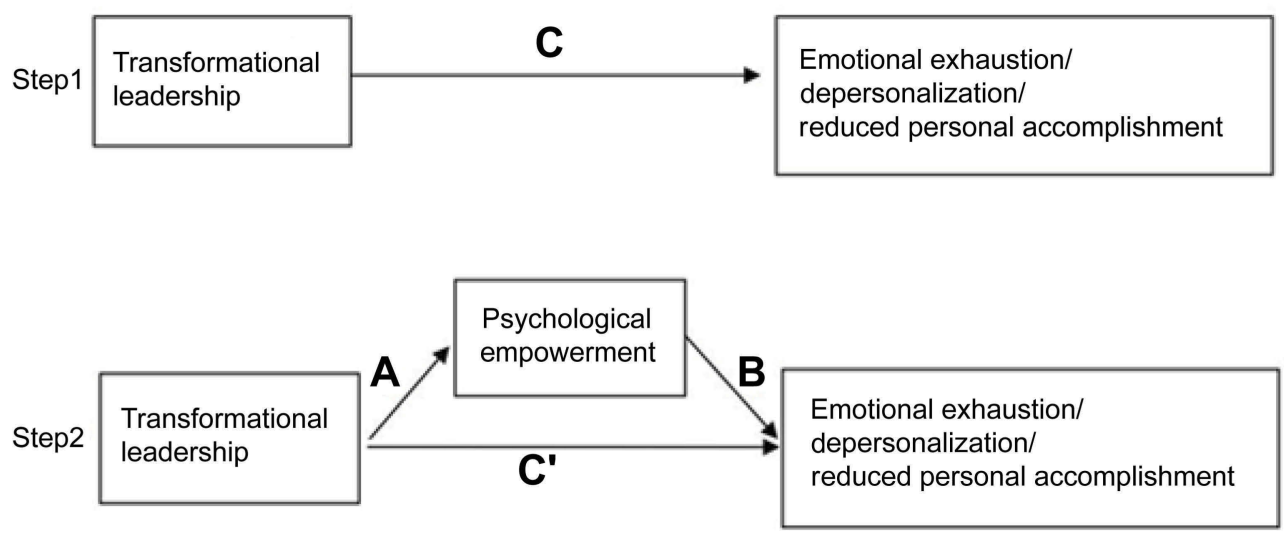

Figure I A theoretical model of the mediating role in the relationship between transformational leadership and occupational burnout subscales. Notes: (A) association of transformational leadership with psychological empowerment; (B) association between psychological empowerment and burnout after controlling for the covariates; (C) association of transformaitonal leadership with burnout; (C') association of transformational leadership with burnout after adding psychological empowerment as a mediator. 


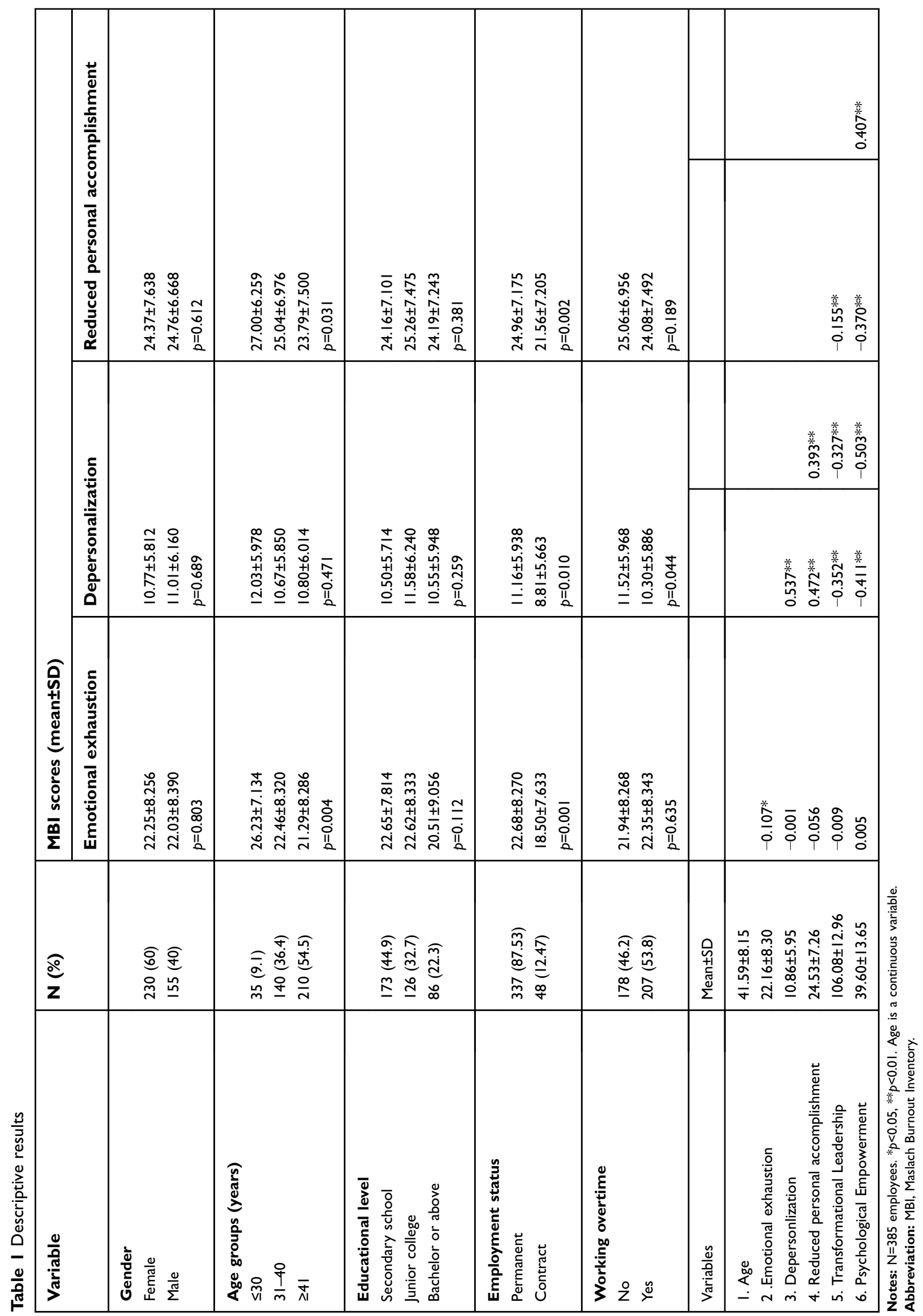


Table 2 The mediating role of psychological empowerment in the association between transformational leadership and emotional exhaustion

\begin{tabular}{|c|c|c|c|}
\hline \multirow[t]{2}{*}{ Variables } & \multicolumn{3}{|c|}{ Emotional exhaustion } \\
\hline & $\begin{array}{l}\text { Step I } \\
(\beta)\end{array}$ & $\begin{array}{l}\text { Step } 2 \\
(\beta)\end{array}$ & $\begin{array}{l}\text { Step } 3 \\
(\beta)\end{array}$ \\
\hline \multicolumn{4}{|l|}{ Step I } \\
\hline Age & $-0.112 *$ & $-0.110^{*}$ & $-0.118^{* *}$ \\
\hline Gender $^{\mathrm{a}}$ & -0.016 & -0.020 & -0.033 \\
\hline Employment status $^{\mathrm{b}}$ & $-0.150 * *$ & $-0.147 * *$ & $-0.122 * *$ \\
\hline \multicolumn{4}{|l|}{ Step 2} \\
\hline $\begin{array}{l}\text { Transformational } \\
\text { leadership }\end{array}$ & & $-0.305 * *$ & $-0.178^{* *}$ \\
\hline \multicolumn{4}{|l|}{ Step 3} \\
\hline Psychological & & & $-0.374 * *$ \\
\hline empowerment & & & \\
\hline Adjusted $\mathrm{R}^{2}$ & 0.032 & 0.124 & 0.246 \\
\hline$\triangle R^{2}$ & $0.040^{* *}$ & $0.093^{* *}$ & $0.123 * *$ \\
\hline
\end{tabular}

Notes: $\mathrm{N}=385$ employees. ${ }^{*} p<0.05,{ }^{*} p<<0.01 .{ }^{a} \mathrm{I}=$ female, $2=$ male. ${ }^{\mathrm{b}} \mathrm{I}=$ =permanent, $2=$ contract. Age is a continuous variable.

empowerment was negatively associated with emotional exhaustion $(\beta=-0.374, p<0.01)$ and psychological empowerment explained $12.3 \%$ of the variance in emotional exhaustion. When psychological empowerment was added, the regression coefficient for transformational leadership decreased (from $\beta=-0.305$ to $\beta=-0.178, p<0.01$ ). This reflects

Table 3 The mediation of psychological empowerment on the association between transformational leadership and depersonalization

\begin{tabular}{|l|l|l|l|}
\hline \multirow{2}{*}{ Variables } & \multicolumn{3}{|l|}{ Depersonalization } \\
\cline { 2 - 4 } & $\begin{array}{l}\text { Step I } \\
\mathbf{( \beta )}\end{array}$ & $\begin{array}{l}\text { Step 2 } \\
\mathbf{( \beta )}\end{array}$ & $\begin{array}{l}\text { Step 3 } \\
\mathbf{( \beta )}\end{array}$ \\
\hline Step I & & & \\
Age & 0.024 & 0.025 & 0.016 \\
Gender $^{\mathrm{a}}$ & 0.034 & 0.030 & 0.016 \\
Employment status $^{\mathrm{b}}$ & $-0.136^{* *}$ & $-0.133^{* *}$ & $-0.104^{*}$ \\
\hline Step 2 & & & \\
Transformational & & $-0.292^{* *}$ & $-0.144^{* *}$ \\
leadership & & & \\
\hline Step 3 & & & \\
Psychological & & & $-0.436^{* *}$ \\
empowerment & & & \\
Adjusted $\mathrm{R}^{2}$ & & 0.094 & 0.261 \\
$\triangle \mathrm{R}^{2}$ & 0.011 & $0.085^{* *}$ & $0.167^{* *}$ \\
\hline
\end{tabular}

Notes: ${ }^{*} p<0.05, * * p<0.01 .{ }^{a} \mid=$ female, $2=$ male. ${ }^{b} \mathrm{I}=$ permanent, $2=$ contract. Age is a continuous variable. that psychological empowerment probably mediated the association between transformational leadership and emotional exhaustion partly.

Table 3 has shown the results of hierarchical regression analysis of depersonalization after controlling demographic variables. It was indicated that transformational leadership was negatively associated with depersonalization. Transformational leadership explained $8.5 \%$ of the variance in depersonalization among CDC employees. In addition, psychological empowerment was negatively associated with depersonalization $(\beta=-0.436, p<0.01)$ and psychological empowerment explained $16.7 \%$ of the variance in depersonalization. When psychological empowerment was added, the regression coefficient for transformational leadership decreased (from $\beta=-0.292$ to $\beta=-0.144, p<0.01$ ). This shows that psychological empowerment probably mediates the association between transformational leadership and depersonalization partly.

Table 4 has shown the results of hierarchical regression analysis of reduced personal accomplishment after controlling demographic variables. It was indicated that transformational leadership was negatively associated with reduced personal accomplishment. Transformational leadership

Table 4 The mediation of psychological empowerment on the association between transformational leadership and reduced personal accomplishment

\begin{tabular}{|c|c|c|c|}
\hline \multirow[t]{2}{*}{ Variables } & \multicolumn{3}{|c|}{$\begin{array}{l}\text { Reduced personal } \\
\text { accomplishment }\end{array}$} \\
\hline & $\begin{array}{l}\text { Step I } \\
(\beta)\end{array}$ & $\begin{array}{l}\text { Step } 2 \\
(\beta)\end{array}$ & $\begin{array}{l}\text { Step } 3 \\
(\beta)\end{array}$ \\
\hline Step I & & & \\
\hline Age & -0.092 & -0.091 & $-0.098^{*}$ \\
\hline Gender $^{a}$ & 0.024 & -0.021 & -0.010 \\
\hline Employment status ${ }^{b}$ & $-0.144 * *$ & $-0.14 \mid * *$ & $-0.119 *$ \\
\hline $\begin{array}{l}\text { Step } 2 \\
\text { Transformational } \\
\text { leadership }\end{array}$ & & $-0.260 * *$ & $-0.145^{* *}$ \\
\hline $\begin{array}{l}\text { Step } 3 \\
\text { Psychological } \\
\text { empowerment }\end{array}$ & & & $-0.338 * *$ \\
\hline Adjusted $\mathrm{R}^{2}$ & 0.026 & 0.091 & 0.191 \\
\hline$\triangle R^{2}$ & $0.034^{* *}$ & $0.067^{* *}$ & $0.100 * *$ \\
\hline
\end{tabular}

Notes: ${ }^{*} p<0.05,{ }^{* *} p<0.01 .{ }^{a} \mid=$ female, $2=$ male. ${ }^{b} \mid=$ epermanent, $2=$ contract. Age is a continuous variable. 
explained $6.7 \%$ of the variance in reduced personal accomplishment among CDC employees. In addition, psychological empowerment was negatively associated with reduced personal accomplishment $(\beta=-0.338, p<0.01)$ and psychological empowerment explained $10.0 \%$ of the variance in reduced personal accomplishment. When psychological empowerment was added, the absolute value of regression coefficient for transformational leadership decreased (from $\beta=-0.260$ to $\beta=-0.145, p<0.01)$. This reveals that psychological empowerment probably mediates the association between transformational leadership and reduced personal accomplishment partly.

We tested the mediating effect of psychological empowerment by bootstrapping method. As shown in Table 5, transformational leadership had a negative association with emotional leadership, depersonalization, and reduced personal accomplishment (the "c path"). Transformational leadership was always positively associated with psychological empowerment (the "a path"). Psychological empowerment had a negative association with emotional exhaustion, depersonalization, and reduced personal accomplishment (the "b path"). B Ca $95 \%$ CI for $\mathrm{a} \times \mathrm{b}$ excluding 0 indicates a significant mediating role of the predictor. So, psychological empowerment played a significant mediating role in the association between the independent variable (transformational leadership) and the dependent variable (emotional exhaustion, depersonalization, or reduced personal accomplishment). Coefficient $(\mathrm{a} \times \mathrm{b} / \mathrm{c})$ was used to assess the proportion of mediation. The proportion of psychological empowerment mediating effect was $41.56 \%$ for emotional exhaustion, $50.62 \%$ for depersonalization, and $44.32 \%$ for reduced personal accomplishment.

\section{Discussion}

Our result that transformational leadership correlated with burnout subscales is broadly in line with those from earlier studies. Leaders with transformational leadership have the characteristics of a lot of virtue, charisma of a leader, visioning, inspiring, and personal care. Then, transformational leaders will provide their subordinates with high level of self-confidence, psychological empowerment, and good vision about the future. As the psychological empowerment of employees is improved, the risk of burnout is lessened. Hildenbrand $\mathrm{K}$ et al have also pointed out that transformational leadership could not only increase job performance beyond expectations but also benefit all employees through increasing well-being. ${ }^{45}$ In addition, trust in the leader, self-efficacy, and meaningfulness of work might play an important mediating role. ${ }^{46,50}$

As far as we know, there are few studies focusing on the mediating role of psychological empowerment between transformational leadership and burnout. Even so, we would like to compare our study with other related research results. For example, Hildenbrand $\mathrm{K}$ et al have examined the moderated mediating role of "employee thriving" on the relationship between transformational leadership with burnout. ${ }^{45}$ While he emphasized that people from East Asians are relatively lower in employees' openness to experience, compared with people from America or Europe. People with low employees' openness to experience might not be sensitive to transformational leadership. To the CDC employees in China, potential mediator "employee thriving" may not be suitable. Therefore, our empirical study offers a noteworthy theoretical contribution about the possible mediator between transformational leadership and burnout. We speculated that transformational leadership might reduce the employees' risk of burnout by promoting the employees' psychological empowerment.

As far as the empirical implications of the findings, we considered that under the unchanged condition of present workload and amount of staff, adjusting leadership to the kind of transformational ones might be a practical and effective countermeasure to relieve the CDC employees' burnout. Decision makers in the CDC should try their best to introduce outstanding talents, change their manager's

Table 5 Bootstrapping test of the indirect effect whether psychological empowerment acts as a potential mediator in the correlation between transformational leadership and burnout subscales

\begin{tabular}{|c|c|c|c|c|c|}
\hline \multirow[t]{2}{*}{ Dependent variable } & \multicolumn{4}{|c|}{ Path coefficients } & \multirow[t]{2}{*}{ a×b (BCa 95\% Cl) } \\
\hline & c & $\mathbf{a}$ & $\mathbf{b}$ & $c^{\prime}$ & \\
\hline Emotional exhaustion & $-0.195^{* *}$ & $0.357^{* *}$ & $-0.227^{* *}$ & $-0.114^{* *}$ & $-0.081(-0.120,-0.047)$ \\
\hline Depersonalization & $-0.134^{* *}$ & $0.357^{* * *}$ & $-0.190 * *$ & $-0.066 * *$ & $-0.068(-0.094,-0.044)$ \\
\hline Reduced personal accomplishment & $-0.145^{* *}$ & $0.357^{* *}$ & $-0.180^{* *}$ & $-0.08 I^{* *}$ & $-0.064(-0.096,-0.038)$ \\
\hline
\end{tabular}

Note: $* * p<0.01$. 
leadership, and strengthen the training for managers. In addition, more attention should be paid to the level of psychological empowerment of CDC employees. To those with low psychological empowerment, the leader should attach more importance to and take all kinds of measures to promote their self-efficacy, sense of responsibility, and initiative. The measures include but are not limited to inspiring and motivating the CDC employees toward the ideas or goals that the organization confronts with; leaders listening to, mentoring and sending feedback to the CDC employees actively, timely, and sincerely. The positive, striving leadership might have association with the enhancement of the CDC employees' perceived value of work, believing of self-competence, self-determination, and perceiving self-impact.

So, to improve the perception of psychological empowerment of employees, managers need to clarify their mission and vision, formulate specific development strategies and plans, and clarify the growth path of employees. Provides employees with challenging work and opportunities to participate in decision making. In addition, the managers also need to establish an employee-oriented corporate culture, create a free, equal and creative organizational atmosphere, and create a working environment where the talents of knowledge employees can be fully displayed. The sharing of information and resources provides employees with opportunities and support for continuous learning and development to improve employees' perception of work meaning, self-efficacy, self-determination, and influence to prevent or reduce the burnout of the employees.

There are several limitations: first, it is a cross-sectional study, we could not draw any causal relationship between variables; second, cross-sectional mediation analysis can produce biased results; ${ }^{47-49}$ third, common methods bias exists. We used similar kind of instruments to collect independent and dependent variables. This bias might inflate the association under the present study; fourth, we have not carried out the multifaceted structure of transformational leadership style and psychological empowerment. This limits our contribution; fifth, we only investigated CDC employees working in a city in the northeast Chinese province, this population could not represent $\mathrm{CDC}$ employees from other regions.

Even so, our study provided a meaningful complement and contribution to the existing theory, existing scientific and government bodies. First, few studies have explored the burnout of CDC employees. As we all know, burnout of service providers will do harm to themselves, the service acceptors, and even the organization. The CDC employees not only prevent and control of diseases but also take part in establishing the emergency response system for discovering the major outbreaks and responding to the public health emergencies. This kind of working environment may bring them heavy tension and pressure which will cause burnout. Second, we make a meaningful supplement to the existing theoretical model. Amarjit S. Gill has indicated that implementing transformational leadership could mitigate stress and burnout of hospitality industry employees; Kenneth $\mathrm{L}$ et al have revealed that transformational leadership and school restructuring might ameliorate the teacher burnout. ${ }^{15}$ Nonetheless, how much variation of burnout among CDC employees could transformational leadership explain has not been explored. And how does transformational leadership mitigate burnout has not been fully studied. We successfully explored the mediating role of psychological empowerment in the association of transformational leadership and burnout although we have not proven the causal effect yet in the present study; it is a cross-sectional study; our results might shed some light on the association of transformational leadership with decreased burnout. Effective solutions and interventions should be developed in the future.

\section{Conclusion}

The present study showed that the level of emotional exhaustion and reduced personal accomplishment among CDC employees in China is very high. It was revealed that age and employment status have a significant relationship with burnout. Our findings also indicated that transformational leadership and psychological empowerment were related to all burnout dimensions negatively. Meanwhile, psychological empowerment has been tested as a mediator of the association between transformational leadership and burnout.

\section{Acknowledgments}

The authors would like to give acknowledgment to all the CDC employees and relevant administrators in the study banks. They have paid much time and vigor in filling out the questionnaires and assisting in obtaining the written informed consent.

\section{Disclosure}

The authors report no conflicts of interest in this work. 


\section{References}

1. Shenoi AN, Kalyanaraman M, Pillai A, Raghava PS, Day S. Burnout and Psychological distress among pediatric critical care physicians in the United States. Crit Care Med. 2018;46(1):116-122. doi:10.1097/ CCM.0000000000002751

2. Dewa CS, Loong D, Bonato S, Trojanowski L. The relationship between physician burnout and quality of healthcare in terms of safety and acceptability: a systematic review. BMJ Open. 2017;7(6): e015141. doi:10.1136/bmjopen-2016-015141

3. Dewa CS, Loong D, Bonato S, Thanh NX, Jacobs P. How does burnout affect physician productivity? A systematic literature review. BMC Health Serv Res. 2014;14:325. doi:10.1186/1472-6963-14-325

4. West CP, Dyrbye LN, Erwin PJ, Shanafelt TD. Interventions to prevent and reduce physician burnout: a systematic review and meta-analysis. Lancet. 2016;388(10057):2272-2281. doi:10.1016/ S0140-6736(16)31279-X

5. Linzer M, Poplau S, Grossman E, et al. A cluster randomized trial of interventions to improve work conditions and clinician burnout in primary care: results from the Healthy Work Place (HWP) study. $J$ Gen Intern Med. 2015;30(8):1105-1111. doi:10.1007/s11606-0153235-4

6. Mor Barak ME, Levin A, Nissly JA, Lane CJ. Why do they leave? Modeling child welfare workers' turnover intentions. Child Youth Serv Rev. 2006;28:548-577. doi:10.1016/j.childyouth.2005.06.003

7. Lioyd C, King R, Chenoweth L. Social work, stress and burnout: a review. J Ment Health. 2002;11(3):255-265. doi:10.1080/09638230020023642

8. Kuoppala J, Lamminpaa A, Liira J, Vainio H. Leadership, job wellbeing, and health effects-a systematic review and a meta-analysis. $J$ Occup Environ Med. 2008;50(8):904-915. doi:10.1097/ JOM.0b013e31817e918d

9. Schyns B, Schilling J. How bad are the effects of bad leaders? A meta-analysis of destructive leadership and its outcomes. Leadership Q. 2013;24(1):138-158. doi:10.1016/j.leaqua.2012.09.001

10. Montano D, Reeske A, Franke F, et al. Leadership, followers' mental health and job performance in organizations: A comprehensive metaanalysis from an occupational health perspective. J Organ Behav. 2017;38(3):327-350. doi:10.1002/job.2124

11. Lowe KB, Kroeck KG, Sivasubramaniam N. Effectiveness correlates of transformational and transactional leadership: meta-analytic review of the literature. Leadership Q. 1996;7(3):385-425. doi:10.1016/S1048-9843(96)90027-2

12. Dvir T, Eden D, Avolio B, Shamir B. Impact of transformational leadership on follower development and performance: a field study. Acad Manage J. 2002;45:735-744.

13. Barling J, Weber T, Kelloway EK. Effects of Transformational Leadership Training on Attitudinal and Financial Outcomes: A Field Experiments. J Appl Psychol. 1996;81(6):827-832. doi:10.1037/00219010.81.6.827

14. Gill AS, Flaschner AB, Shachar M. Mitigating stress and burnout by implementing transformational-leadership. Int J Contemp Hosp Manage. 2006;18(6):469-481. doi:10.1108/09596110610681511

15. Kenneth L, Teresa M, Doris J, Jennifer L. School restructuring, transformational leadership and the amelioration of teacher burnout. Anxiety Stress Coping. 2007;9(3):199-215. doi:10.1080/10615809608249402

16. Rittschof KR, Fortunato VJ. The influence of transformational leadership and job burnout on child protective services case managers' commitment and intent to quit. J Soc Serv Res. 2016;42(3):372385. doi:10.1080/01488376.2015.1101047

17. Annebel HB, De Hoogh DN, Hartog D. Neuroticism and locus of control as moderators of the relationships of charismatic and autocratic leadership with Burnout. J Appl Psychol. 2009;94(4):10581067. doi:10.1037/a0016253
18. Ebrahimzade N, Mooghali A, Lankarani KB, Kalateh Sadati A. Relationship between nursing managers' leadership styles and nurses' job burnout: a study at Shahid Dr. Faghihi Hospital, Shiraz, Iran. Shiraz E Med J. 2015;16(8):e270270. doi:10.17795/semj

19. Hetland H, Sandal GM, Johnsen TB. Burnout in the information technology sector: does leadership matter. Eur $J$ Work Organ Psychol. 2007;16(1):58-75. doi:10.1080/13594320601084558

20. Salem IE. Transformational leadership: relationship to job stress and job burnout in five-star hotels. Tourism Hospitality Res. 2015;15 (4):1-14. doi:10.1177/1467358415581445

21. Holstad TJ, Korek S, Rigotti T, Mohr G. The relation between transformational leadership and follower emotional strain: the moderating role of professional ambition. Leadership. 2014;10(3):269. doi: $10.1177 / 1742715013476083$

22. Avolio BJ, Zhu W, Koh W, Bhatia P. Transformational leadership and organizational commitment: mediating role of psychological empowerment and moderating role of structural distance. J Organ Behav. 2004;25(8):951-968. doi:10.1002/(ISSN)1099-1379

23. Dong IJ, Sosik JJ. Transformational leadership in work groups: the role of empowerment, cohesiveness, and collective-efficacy on perceived group performance. Small Group Res. 2002;33(3):313-336. doi: $10.1177 / 10496402033003002$

24. Fuller JB, Morrison R, Jones L, Bridger D, Brown V. The effects of psychological empowerment on transformational leadership and job satisfaction. J Socl Psychol. 1999;139(3):389-391. doi:10.1080/ 00224549909598396

25. Castro CB, Mmv P, Bueno JCC. Transformational leadership and followers' attitudes: the mediating role of psychological empowerment. Int J Human Resour Manage. 2008;19(10):1842-1863. doi:10.1080/09585190802324601

26. Thomas KW, Velthouse BA. Cognitive elements of empowerment: an "Interpretive" model of intrinsic task motivation. Acad Manage Rev. 1990;15(4):666-681. doi:10.2307/258687

27. Greco P, Laschinger HK, Wong C. Leader empowering behaviours, staff nurse empowerment and work engagement/burnout. Nurs Leadersh. 2006;19(4):41-56. PMID: 17265673. doi:10.12927/ cjn1.2006.18599

28. O'Brien JL. Relationships among structural empowerment, psychological empowerment, and burnout in registered staff nurses working in outpatient dialysis centers. Nephrol Nurs J. 2011;38(6):475-481. PMID: 22338940

29. Sarmiento TP, Laschinger HK, Iwasiw C. Nurse educators' workplace empowerment, burnout, and job satisfaction: testing Kanter's theory. $J$ Adv Nurs. 2004;46(2):134-143. doi:10.1111/j.13652648.2003.02973.x

30. Boudrias JS, Morin AJ, Brodeur MM. Role of psychological empowerment in the reduction of burnout in Canadian healthcare workers. Nurs Health Sci. 2012;14(1):8-17. doi:10.1111/j.14422018.2011.00650.x

31. Allameh SM, Heydari M, Davoodi SMR. Studying the relationship between transformational leadership and psychological empowerment of teachers in Abade Township. Procedia Soc Behav Sci. 2012;31(31):224-230. doi:10.1016/j.sbspro.2011.12.046

32. Gómez-Urquiza JL, Aneas-López AB, Fuente-Solana EI, AlbendínGarcía L, Díaz-Rodríguez L, Fuente GA. Prevalence, risk factors, and levels of Burnout among oncology nurses: a systematic review. Oncol Nurs Forum. 2016;43(3):E104-E120. doi:10.1188/16.ONF.E104E120

33. Hyman SA, Michaels DR, Berry JM, et al. Risk of burnout in perioperative clinicians: a survey study and literature review. Anesthesiology. 2011. 114(1):194-204. doi:10.1097/ALN.0b013e318201ce9a

34. Beckstead JW. Confirmatory factor analysis of the Maslach Burnout Inventory among Florida nurses. Int J Nurs Stud. 2002;39(8):785792. doi:10.1016/S0020-7489(02)00012-3 
35. Gil-Monte PR. Factorial validity of the Maslach Burnout Inventory (MBI-HSS) among Spanish professionals. Rev De Saude Public. 2005;39(1):1-8. doi:S0034-89102005000100001

36. Elbarazi I, Loney T, Yousef S, Elias A. Prevalence of and factors associated with burnout among health care professionals in Arab countries: a systematic review. BMC Health Serv Res. 2017;17 (1):491. doi:10.1186/s12913-017-2319-8

37. Szigeti R, Balázs N, Bikfalvi R, Urbán R. Burnout and depressive symptoms in teachers: factor structure and construct validity of the Maslach Burnout inventory-educators survey among elementary and secondary school teachers in Hungary. Stress Health. 2017;33 (5):530-539. doi:10.1002/smi.2737

38. Li L. Study on job burnout and its influencing factors among medical staff for tuberculosis prevention and treatment from different heath facilities in Yunnan province. [Master degree dissertation]. Yunnan Medical University, 2016. (Chinese).

39. Zhang XC, Huang DS, Guan P. Job burnout among critical care nurses from 14 adult intensive care units in Northeastern China: a cross-sectional survey. BMJ Open. 2014;4(6):e004813. doi:10.1136/ bmjopen-2014-004813

40. Bass BM. Leadership and Performance beyond Expectations. New York: Free Press; 1985.

41. Li CP, Shi K. The structure and measurement of transformational leadership in China. Acta Psychol Sin. 2005;37(6):803-811. doi:10.1007/s11782-008-0032-5

42. Liu H, Dou Y, Liu ZJ. Effects of transformational leadership on counter productive work behavior. J Shenyang Aerosp Univ. 2012;29(6):17-20. (Chinese)
43. Wang SS, Liu YH, Yang JH. Relationship among professional nursing practice environment, psychological empowerment and nurses' work engagement. Chin J Nurs. 2012;47(9):834-837. (Chinese)

44. Preacher KJ, Hayes AF. Asymptotic and resampling strategies for assessing and comparing indirect effects in multiple mediator models. Behav Res Methods. 2008;40(3):879-891. doi:10.3758/BRM.40.3.879

45. Hildenbrand K, Sacramento CA, Binnewies C. Transformational leadership and Burnout: the role of thriving and followers' openness to experience. J Occup Health Psychol. 2016;23(1):31-43. doi:10.1037/ocp0000051

46. Liu J, Siu OL, Shi K. Transformational leadership and employee wellbeing: the mediating role of trust in the leader and self-efficacy. Appl Psychol. 2010;59:454 479. doi:10.1111/j.1464-0597.2009.00407.x

47. Maxwell SE, Cole DA. Bias in cross-sectional analyses of longitudinal mediation. Psychol Methods. 2007;12(1):23-44. doi:10.1037/ 1082-989X.12.1.23

48. Maxwell SE, Cole DA, Mitchell MA. Bias in cross-sectional analyses of longitudinal mediation: partial and complete mediation under an autoregressive model. Multivariate Behav Res. 2011;46:816-841. doi:10.1080/00273171.2011.606716

49. Podsakoff PM, MacKenzie SB, Podsakoff NP. Sources of method bias in social science research and recommendations on how to control it. Annu Rev Psychol. 2012;63:539-569. doi:10.1146/ annurev-psych-120710-100452

50. Ka A, Turner N, Barling J, Kelloway EK, McKee MC. Transformational leadership and psychological well-being: the mediating role of meaningful work. J Occup Health Psychol. 2007;12 (3):193-203. doi:10.1037/1076-8998.12.3.193
Psychology Research and Behavior Management

\section{Publish your work in this journal}

Psychology Research and Behavior Management is an international, peer-reviewed, open access journal focusing on the science of psychology and its application in behavior management to develop improved outcomes in the clinical, educational, sports and business arenas. Specific topics covered in the journal include: Neuroscience, memory and decision making; Behavior modification and management; Clinical applications; Business and sports performance management; Social and developmental studies; Animal studies. The manuscript management system is completely online and includes a very quick and fair peer-review system, which is all easy to use. Visit http://www. dovepress.com/testimonials.php to read real quotes from published authors. 